\title{
Fight against COVID-19: A global outbreak response management perfor- mance view
}

\author{
Javid Jouzdani ${ }^{\mathbf{a}^{*}}$
}

${ }^{a}$ Department of Industrial Engineering, Golpayegan University of Technology, Golpayegan, Iran

\section{H R O N I C L E \\ A B S T R A C T}

Article history:

Received: March 62020

Received in revised format:

March 72020

Accepted: March 82020

Available online:

March 82020

Keywords:

COVID-19

Outbreak Response Management

Statistical Data Analysis

\begin{abstract}
Outbreak response can be viewed as a project for which the window of opportunity for planning is often quite limited. Therefore, regular evaluation for sharing the lessons learned is crucial, especially in the cases of national and global crises. As one of the major global concerns, the novel coronavirus, also known as COVID-19, has infected and killed many people in several countries worldwide. Hence, it is worth analyzing the performance of different countries in this regard. In this paper, the confirmed Case Fatality Rate (cCFR), and the confirmed Case Recovery Rate (cCRR) are considered as the main performance criteria, and the data are analyzed utilizing statistical confidence intervals (CIs) implemented in Python. The results identify the regions with high cCFR and low cCRR, as well as the regions with low cCFR and high cCRR. Finally, it is suggested to systematically transfer the knowledge and lessons learned from the high performing countries to where such information and knowledge is needed.
\end{abstract}

\section{Introduction}

Human societies have always been subject to disasters. One of the most impacting is the outbreaks, from the plague in 541 (Rosen, 2010) to the recent Coronavirus Disease outbreak in 2019 (Velavan \& Meyer, 2020), known as COVID-19. Other viruses of this kind had already infected and killed many people. For instance, Severe Acute Respiratory Symptom (SARS) outbreak left more than 700 dead with more than 8,000 cases (CHAN-YEUNG \& XU, 2003), and Middle-East SARS (MERS) led to the death of more than 800 people with more than 2,400 cases. COVID-19 is known to be more contagious, and its death toll surpassed 3,400 people with more than 100,000 cases world-wide on 7 Mar. 2020. It is clear that COVID-19 has a much more significant global impact. Therefore, outbreak response management and lessons learned sharing plays a crucial role in controlling the situation.

Evaluating the situation in infected countries can help to determine the countries with severe conditions as well as those in which the taken measures have been more effective. The identification of the aforementioned conditions and measures can be utilized to define actions to deal with

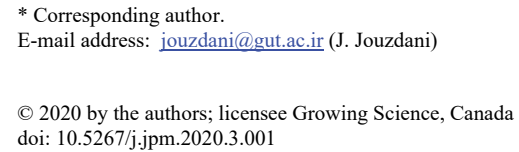


COVID-19 more effectively and efficiently. One of the Case Fatality Rate (CFR), which can be expressed as the risk of death among confirmed cases, is an important indicator of the severity of the epidemic disease (Ghani et al., 2005). Estimating the CFR using the death rate of the confirmed cases (cCFR) is a reliable method for assessing the severity of the outbreaks (Nishiura, Klinkenberg, Roberts, \& Heesterbeek, 2009).

In this paper, cCFR along with the recovery rate of confirmed cases (cCRR) are utilized to assess the situation in different countries. Statistical CI is applied to the data using the Python programming language, and the results are presented. The exposition of the paper is as follows. In the next section, the method of research is presented, in Section 3, the numerical results are discussed, and finally, Section 4 concludes the paper.

\section{Material and Method}

In this section, the methods and the data used to present the results are discussed. Since the methods are conventional well-known statistical methods, they are described briefly.

\subsection{Statistical CIs}

The main tool used to analyze the data are the statistical CI analyses for the proportion of the confirmed cases that die/recover. The CI for the proportion of observations, $p$, in a random sample of size $n$ that belongs to a class of interest is as follows when the sample size is large enough and $p$ is not too close to either 0 or 1 .

$$
\hat{p}-z_{\alpha / 2} \sqrt{\frac{\hat{p}(1-\hat{p})}{n}} \leq p \leq \hat{p}+z_{\alpha / 2} \sqrt{\frac{\hat{p}(1-\hat{p})}{n}}
$$

In the above inequality, $\hat{p}$ is the estimator of $p$ and $z_{\alpha / 2}$ is the upper $\alpha / 2$ percentage of the standard normal distribution (Montgomery \& Runger, 2010).

\subsection{The Data}

The data are used in this research is provided by Johns Hopkins University Center for Systems Science and Engineering (2020). The dataset includes 3395 temporal records of confirmed cases, deaths, and recovered cases for 90 distinct country names from 22 Jan. 2020 to 7 Mar. 2020.

\section{The Results and Discussion}

In this paper, the CI given in Eq. (1) is used to analyze cCFR and cCRR assuming that the sample size, i.e., the number of confirmed cases is large enough; especially for the countries with many infected cases. In addition, according to a recent research by Jung et al. (2020), the 95\% CI for cCFR for COVID-19 is estimated to be $(3.5 \%, 7.5 \%)$ in one scenario, and $(5.3 \%, 12.3 \%)$ in another, allowing us to use the CI approximation in Eq.(1). Therefore, the data are analyzed in Jupyter Notebook using Pandas, Numpy, and Pyplot packages in Python ${ }^{1}$. The charts in Fig. 1 show the calculated CIs for the cCFR and cCRR for the 35 most affected countries on 7 Mar. 2020. This Figure shows the difference among the mean cCFR and cCRR and the corresponding CI which indicates the statistically significant differences. This analysis is presented to propose a method to visualize the differences among the cCFR and cCRR in different countries.

\footnotetext{
${ }^{1}$ The code for the and several other visualizations are available at https://github.com/javid-jouzdani/COVID-19
} 

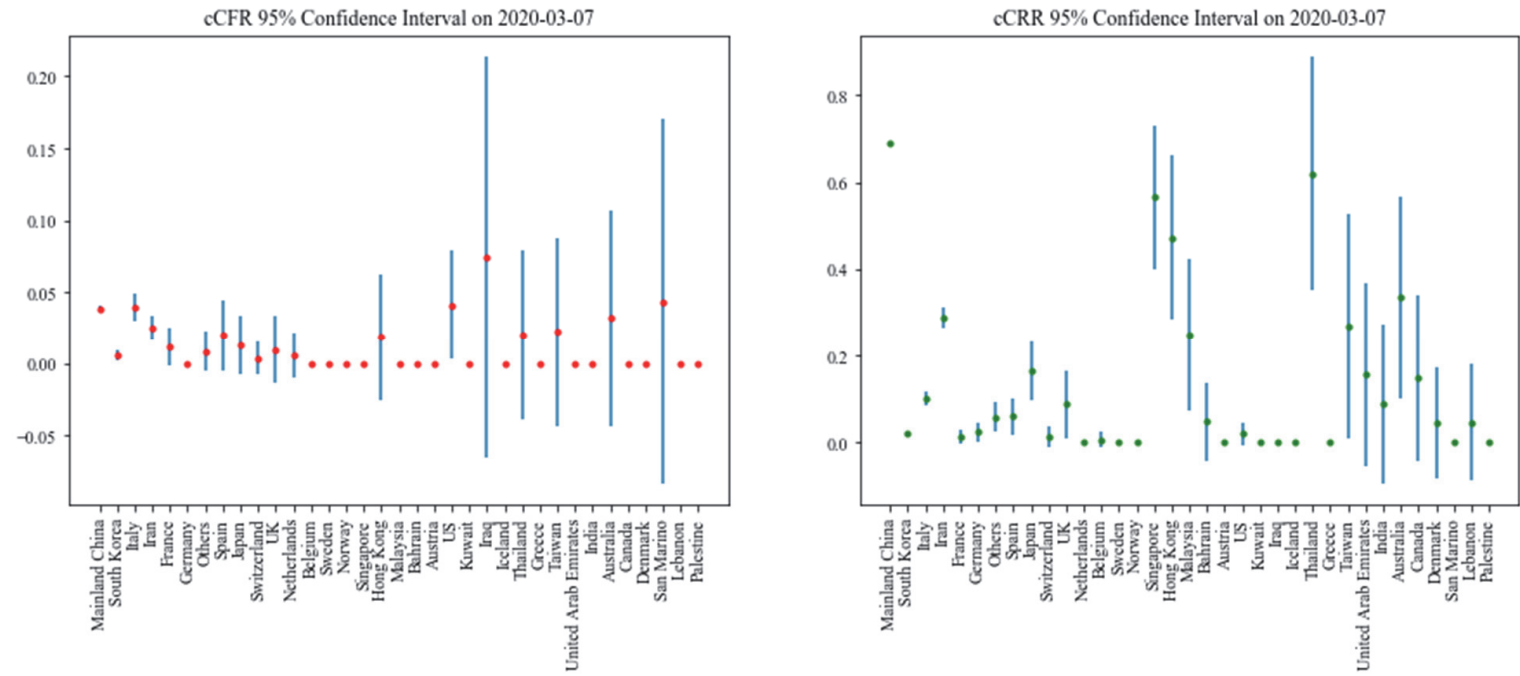

Fig. 1. The CIs plot of cCFR and cCRR for the 35 most affected countries on 7 Mar. 2020
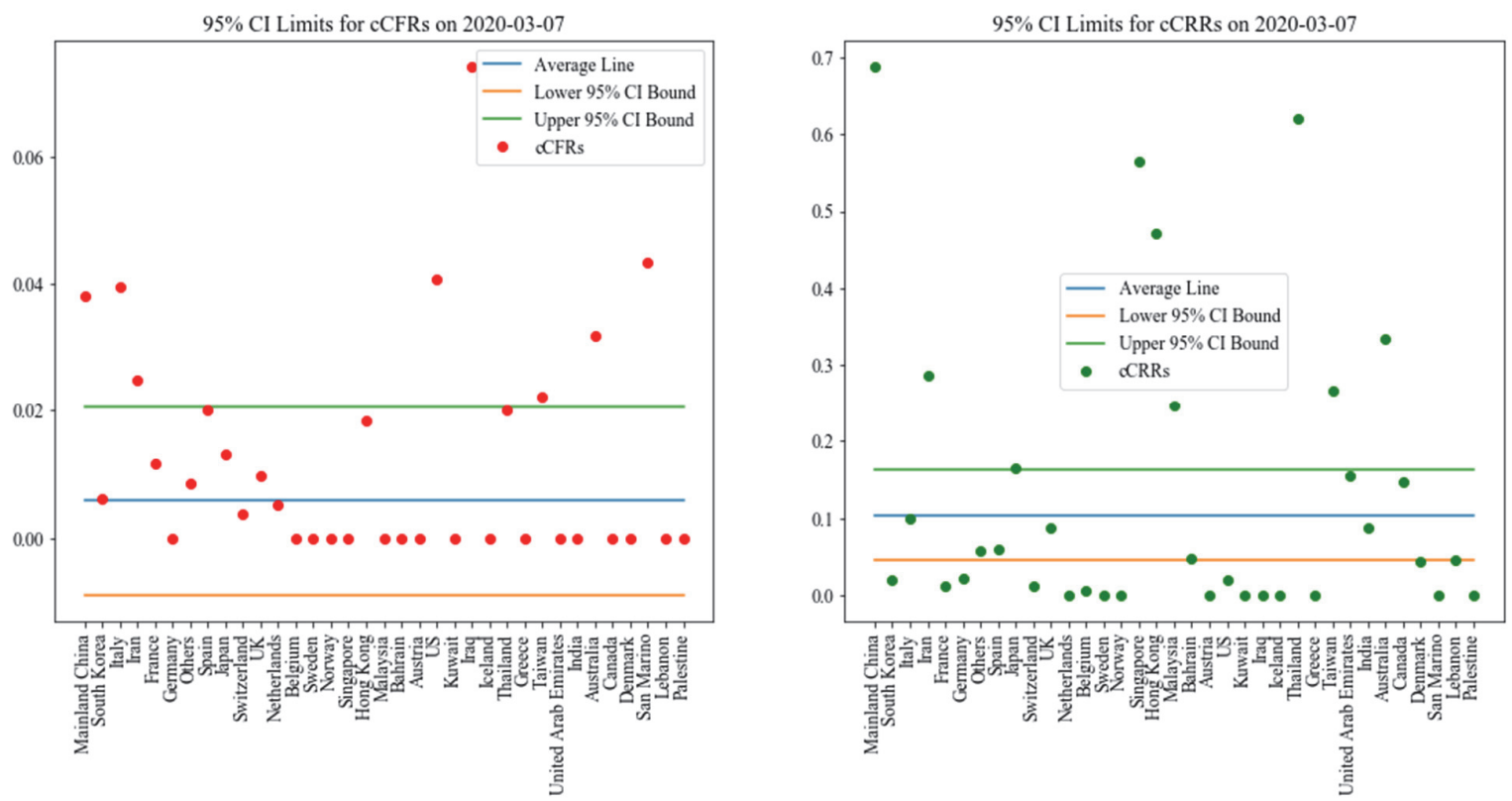

Fig. 2. The cCFR and cCRR for the 35 most affected countries on 7 Mar. 2020 along with the 95\% CI for the overall cCFR and cCRR

In addition, Fig. 2 presents the 95\% CI lines for the cCFR and cCRR in different countries on 7 Mar. 2020 and designates the corresponding cCFR and cCRR for each of the 35 most affected countries. On this particular date, it can be observed that China, Italy, Iran, US, Iraq, Taiwan, Australia, San Marino, and Philippines have a cCFR higher than the upper bound of 95\% CI for the overall cCFR while China, Iran, Japan, Singapore, Hong Kong, Malaysia, Thailand, Taiwan, Australia, Vietnam, Macau, Romania, Mexico, Philippines, Cambodia, Nepal, and Sri Lanka have a cCRR higher than the upper bound of $95 \%$ CI for the overall cCRR. In this paper, the former are called the high cCFR countries and the latter are called the high cCRR countries. From evaluation perspective it is interesting to consider the countries which have high cCFR and low cCRR. These countries are the ones that need to be monitored and helped more carefully. Performing a similar operation for different dates reveals the situation of countries through time. Table 1 presents the information for these countries based on the data. From the Table, it can be seen that Iran was in such condition for several days; however, it is no longer in the list. The high cCFR for this country on .20 Feb. 2020 can be explained by a lack of diagnosis tools and technologies needed to identify and confirm cases of COVID-19. In addition, the United States, Iraq, and San Marino have high cCFR and low cCRR from 2 Mar. 2020. 
Table 1

Data for the countries with high cCFR and low cCRR

\begin{tabular}{|c|c|c|c|c|c|c|c|c|c|c|}
\hline \multirow[b]{2}{*}{ Date } & \multirow[b]{2}{*}{ Country } & \multirow{2}{*}{ Ü } & \multirow[b]{2}{*}{ 气气 } & \multirow{2}{*}{ 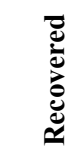 } & \multirow[b]{2}{*}{ cCFR } & \multirow[b]{2}{*}{ cCRR } & \multicolumn{2}{|c|}{$95 \%$ CI for cCFR } & \multicolumn{2}{|c|}{ 95\% CI for cCRR } \\
\hline & & & & & & & 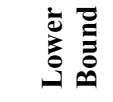 & 离 & 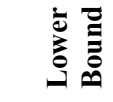 & 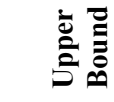 \\
\hline \multirow{3}{*}{$3 / 7 / 2020$} & US & 417 & 17 & 8 & $4.08 \%$ & $1.92 \%$ & $2.18 \%$ & $5.97 \%$ & $0.60 \%$ & $3.24 \%$ \\
\hline & Iraq & 54 & 4 & 0 & $7.41 \%$ & $0.00 \%$ & $0.42 \%$ & $14.39 \%$ & $0.00 \%$ & $0.00 \%$ \\
\hline & San Marino & 23 & 1 & 0 & $4.35 \%$ & $0.00 \%$ & $0.00 \%$ & $12.68 \%$ & $0.00 \%$ & $0.00 \%$ \\
\hline \multirow{3}{*}{$3 / 6 / 2020$} & US & 278 & 14 & 8 & $5.04 \%$ & $2.88 \%$ & $2.47 \%$ & $7.61 \%$ & $0.91 \%$ & $4.84 \%$ \\
\hline & Iraq & 40 & 3 & 0 & $7.50 \%$ & $0.00 \%$ & $0.00 \%$ & $15.66 \%$ & $0.00 \%$ & $0.00 \%$ \\
\hline & San Marino & 21 & 1 & 0 & $4.76 \%$ & $0.00 \%$ & $0.00 \%$ & $13.87 \%$ & $0.00 \%$ & $0.00 \%$ \\
\hline \multirow{3}{*}{$3 / 5 / 2020$} & US & 221 & 12 & 8 & $5.43 \%$ & $3.62 \%$ & $2.44 \%$ & $8.42 \%$ & $1.16 \%$ & $6.08 \%$ \\
\hline & Iraq & 35 & 2 & 0 & $5.71 \%$ & $0.00 \%$ & $0.00 \%$ & $13.40 \%$ & $0.00 \%$ & $0.00 \%$ \\
\hline & San Marino & 21 & 1 & 0 & $4.76 \%$ & $0.00 \%$ & $0.00 \%$ & $13.87 \%$ & $0.00 \%$ & $0.00 \%$ \\
\hline \multirow{3}{*}{$3 / 4 / 2020$} & San Marino & 16 & 1 & 0 & $6.25 \%$ & $0.00 \%$ & $0.00 \%$ & $18.11 \%$ & $0.00 \%$ & $0.00 \%$ \\
\hline & Iraq & 35 & 2 & 0 & $5.71 \%$ & $0.00 \%$ & $0.00 \%$ & $13.40 \%$ & $0.00 \%$ & $0.00 \%$ \\
\hline & US & 153 & 11 & 8 & $7.19 \%$ & $5.23 \%$ & $3.10 \%$ & $11.28 \%$ & $1.70 \%$ & $8.76 \%$ \\
\hline $3 / 2 / 2020$ & US & 101 & 6 & 7 & $5.94 \%$ & $6.93 \%$ & $1.33 \%$ & $10.55 \%$ & $1.98 \%$ & $11.88 \%$ \\
\hline $2 / 25 / 2020$ & Iran & 95 & 16 & 0 & $16.84 \%$ & $0.00 \%$ & $9.32 \%$ & $24.37 \%$ & $0.00 \%$ & $0.00 \%$ \\
\hline $2 / 24 / 2020$ & Iran & 61 & 12 & 0 & $19.67 \%$ & $0.00 \%$ & $9.70 \%$ & $29.65 \%$ & $0.00 \%$ & $0.00 \%$ \\
\hline $2 / 23 / 2020$ & Iran & 43 & 8 & 0 & $18.60 \%$ & $0.00 \%$ & $6.97 \%$ & $30.24 \%$ & $0.00 \%$ & $0.00 \%$ \\
\hline $2 / 22 / 2020$ & Iran & 28 & 5 & 0 & $17.86 \%$ & $0.00 \%$ & $3.67 \%$ & $32.04 \%$ & $0.00 \%$ & $0.00 \%$ \\
\hline $2 / 21 / 2020$ & Iran & 18 & 4 & 0 & $22.22 \%$ & $0.00 \%$ & $3.02 \%$ & $41.43 \%$ & $0.00 \%$ & $0.00 \%$ \\
\hline $2 / 20 / 2020$ & Iran & 5 & 2 & 0 & $40.00 \%$ & $0.00 \%$ & $0.00 \%$ & $82.94 \%$ & $0.00 \%$ & $0.00 \%$ \\
\hline
\end{tabular}

Correspondingly, it is worth identifying the countries with low cCFR and high cCRR. These are the countries that most probably have taken effective and efficient measures for outbreak response management. Table 2 presents the data for these countries from 5 Mar. 2020 to 7 Mar. 2020. The Table is truncated due to the large number of records. The analysis of the full Table reveals that Singapore, Malaysia, Vietnam, and Macau have low cCFR and high cCRR for many days.

Table 2

Data for the countries with low cCFR and high cCRR

\begin{tabular}{|c|c|c|c|c|c|c|c|c|c|c|}
\hline \multirow[b]{2}{*}{ Date } & \multirow[b]{2}{*}{ Country } & \multirow{2}{*}{ 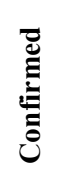 } & \multirow[b]{2}{*}{ } & \multirow{2}{*}{ 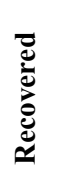 } & \multirow[b]{2}{*}{ cCFR } & \multirow[b]{2}{*}{ cCRR } & \multicolumn{2}{|c|}{ 95\% CI for CCFR } & \multicolumn{2}{|c|}{ 95\% CI for cCRR } \\
\hline & & & & & & & 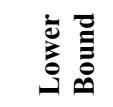 & $\begin{array}{l}\grave{d} \\
\grave{\Xi} \\
\grave{D}\end{array}$ & 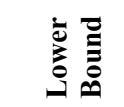 & 它 \\
\hline \multirow{9}{*}{$3 / 7 / 2020$} & Singapore & 138 & 0 & 78 & $0.00 \%$ & $56.52 \%$ & $0.00 \%$ & $0.00 \%$ & $48.25 \%$ & $64.79 \%$ \\
\hline & Malaysia & 93 & 0 & 23 & $0.00 \%$ & $24.73 \%$ & $0.00 \%$ & $0.00 \%$ & $15.96 \%$ & $33.50 \%$ \\
\hline & Vietnam & 18 & 0 & 16 & $0.00 \%$ & $88.89 \%$ & $0.00 \%$ & $0.00 \%$ & $74.37 \%$ & $103.41 \%$ \\
\hline & Macau & 10 & 0 & 10 & $0.00 \%$ & $100.00 \%$ & $0.00 \%$ & $0.00 \%$ & $100.00 \%$ & $100.00 \%$ \\
\hline & Romania & 9 & 0 & 3 & $0.00 \%$ & $33.33 \%$ & $0.00 \%$ & $0.00 \%$ & $2.53 \%$ & $64.13 \%$ \\
\hline & Mexico & 6 & 0 & 1 & $0.00 \%$ & $16.67 \%$ & $0.00 \%$ & $0.00 \%$ & $0.00 \%$ & $46.49 \%$ \\
\hline & Cambodia & 1 & 0 & 1 & $0.00 \%$ & $100.00 \%$ & $0.00 \%$ & $0.00 \%$ & $100.00 \%$ & $100.00 \%$ \\
\hline & Nepal & 1 & 0 & 1 & $0.00 \%$ & $100.00 \%$ & $0.00 \%$ & $0.00 \%$ & $100.00 \%$ & $100.00 \%$ \\
\hline & Sri Lanka & 1 & 0 & 1 & $0.00 \%$ & $100.00 \%$ & $0.00 \%$ & $0.00 \%$ & $100.00 \%$ & $100.00 \%$ \\
\hline
\end{tabular}


Table 3

Data for the countries with low cCFR and high cCRR (Continued)

\begin{tabular}{|c|c|c|c|c|c|c|c|c|c|c|}
\hline \multirow[b]{2}{*}{ Date } & \multirow[b]{2}{*}{ Country } & \multirow{2}{*}{ 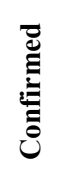 } & \multirow[b]{2}{*}{ } & \multirow{2}{*}{ 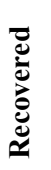 } & \multirow[b]{2}{*}{ cCFR } & \multirow[b]{2}{*}{ cCRR } & \multicolumn{2}{|c|}{ 95\% CI for cCFR } & \multicolumn{2}{|c|}{ 95\% CI for cCRR } \\
\hline & & & & & & & 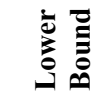 & 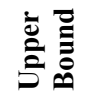 & فَّْ & 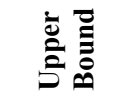 \\
\hline \multirow{9}{*}{$3 / 6 / 2020$} & Singapore & 130 & 0 & 78 & $0.00 \%$ & $60.00 \%$ & $0.00 \%$ & $0.00 \%$ & $51.58 \%$ & $68.42 \%$ \\
\hline & Malaysia & 83 & 0 & 22 & $0.00 \%$ & $26.51 \%$ & $0.00 \%$ & $0.00 \%$ & $17.01 \%$ & $36.00 \%$ \\
\hline & United Arab Emirates & 29 & 0 & 5 & $0.00 \%$ & $17.24 \%$ & $0.00 \%$ & $0.00 \%$ & $3.49 \%$ & $30.99 \%$ \\
\hline & Vietnam & 16 & 0 & 16 & $0.00 \%$ & $100.00 \%$ & $0.00 \%$ & $0.00 \%$ & $100.00 \%$ & $100.00 \%$ \\
\hline & Macau & 10 & 0 & 10 & $0.00 \%$ & $100.00 \%$ & $0.00 \%$ & $0.00 \%$ & $100.00 \%$ & $100.00 \%$ \\
\hline & Mexico & 6 & 0 & 1 & $0.00 \%$ & $16.67 \%$ & $0.00 \%$ & $0.00 \%$ & $0.00 \%$ & $46.49 \%$ \\
\hline & Cambodia & 1 & 0 & 1 & $0.00 \%$ & $100.00 \%$ & $0.00 \%$ & $0.00 \%$ & $100.00 \%$ & $100.00 \%$ \\
\hline & Nepal & 1 & 0 & 1 & $0.00 \%$ & $100.00 \%$ & $0.00 \%$ & $0.00 \%$ & $100.00 \%$ & $100.00 \%$ \\
\hline & Sri Lanka & 1 & 0 & 1 & $0.00 \%$ & $100.00 \%$ & $0.00 \%$ & $0.00 \%$ & $100.00 \%$ & $100.00 \%$ \\
\hline \multirow{10}{*}{$3 / 5 / 2020$} & Singapore & 117 & 0 & 78 & $0.00 \%$ & $66.67 \%$ & $0.00 \%$ & $0.00 \%$ & $58.12 \%$ & $75.21 \%$ \\
\hline & Malaysia & 50 & 0 & 22 & $0.00 \%$ & $44.00 \%$ & $0.00 \%$ & $0.00 \%$ & $30.24 \%$ & $57.76 \%$ \\
\hline & Vietnam & 16 & 0 & 16 & $0.00 \%$ & $100.00 \%$ & $0.00 \%$ & $0.00 \%$ & $100.00 \%$ & $100.00 \%$ \\
\hline & Macau & 10 & 0 & 9 & $0.00 \%$ & $90.00 \%$ & $0.00 \%$ & $0.00 \%$ & $71.41 \%$ & $108.59 \%$ \\
\hline & Mexico & 5 & 0 & 1 & $0.00 \%$ & $20.00 \%$ & $0.00 \%$ & $0.00 \%$ & $0.00 \%$ & $55.06 \%$ \\
\hline & Russia & 4 & 0 & 2 & $0.00 \%$ & $50.00 \%$ & $0.00 \%$ & $0.00 \%$ & $1.00 \%$ & $99.00 \%$ \\
\hline & Egypt & 3 & 0 & 1 & $0.00 \%$ & $33.33 \%$ & $0.00 \%$ & $0.00 \%$ & $0.00 \%$ & $86.68 \%$ \\
\hline & Cambodia & 1 & 0 & 1 & $0.00 \%$ & $100.00 \%$ & $0.00 \%$ & $0.00 \%$ & $100.00 \%$ & $100.00 \%$ \\
\hline & Nepal & 1 & 0 & 1 & $0.00 \%$ & $100.00 \%$ & $0.00 \%$ & $0.00 \%$ & $100.00 \%$ & $100.00 \%$ \\
\hline & Sri Lanka & 1 & 0 & 1 & $0.00 \%$ & $100.00 \%$ & $0.00 \%$ & $0.00 \%$ & $100.00 \%$ & $100.00 \%$ \\
\hline
\end{tabular}

In order to depict the latest global situation, Fig. 3 shows the cCFR, and Fig. 4 illustrates the cCRR. These Figures provide a visual on the above findings.

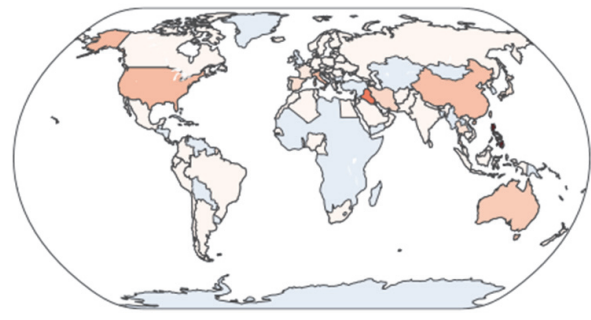

Fig. 3. Global view of cCFR on 7 Mar. 2020
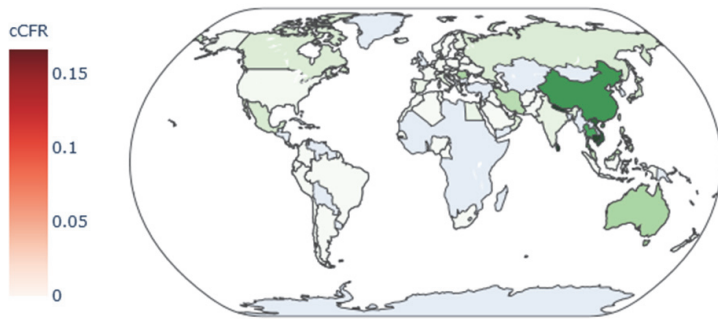

Fig. 4. Global view of cCRR on 7 Mar. 2020

\section{Conclusions}

In this paper, a brief evaluation of the global fight against COVID-19 using confidence interval and the temporal confirmed, death, and recovered cases data was presented. The analyses presented a method to visualize and distinguish the countries with conditions that call for close monitoring and international attention. The results indicate that Iran, the United States, Iraq, and San Marino are the regions that need such attention while Singapore, Malaysia, Vietnam, and Macau are the ones performed most effectively and efficiently in outbreak response management. The suggestion is 
that organizations such as World Health Organization and Centers for Disease Control and Prevention systematically transfer the lessons learned from the countries with low cCFR and high cCRR to those with high cCFR and low cCRR.

\section{Acknowledgements}

I would like to thank my dear wife for her support and patience. Especially these days during which we were all at home to avoid COVID-19 infection, and busy with research most of the time.

\section{References}

CHAN-YEUNG, M., \& XU, R.-H. (2003). SARS: epidemiology. Respirology, 8(s1), S9-S14.

Ghani, A. C., Donnelly, C. A., Cox, D. R., Griffin, J. T., Fraser, C., Lam, T. H., . . Leung, G. M. (2005). Methods for Estimating the Case Fatality Ratio for a Novel, Emerging Infectious Disease. American Journal of Epidemiology, 162(5), 479-486. doi: 10.1093/aje/kwi230

Johns Hopkins University Center for Systems Science and Engineering. (2020). 2019 Novel Coronavirus COVID-19 (2019-nCoV) Data Repository by Johns Hopkins CSSE. 2020, from https://github.com/CSSEGISandData/COVID-19

Jung, S.-m., Akhmetzhanov, A. R., Hayashi, K., Linton, N. M., Yang, Y., Yuan, B., . . Nishiura, H. (2020). Real-Time Estimation of the Risk of Death from Novel Coronavirus (COVID-19) Infection: Inference Using Exported Cases. Journal of Clinical Medicine, 9(2), 523.

Montgomery, D. C., \& Runger, G. C. (2010). Applied statistics and probability for engineers: John Wiley \& Sons.

Nishiura, H., Klinkenberg, D., Roberts, M., \& Heesterbeek, J. A. P. (2009). Early Epidemiological Assessment of the Virulence of Emerging Infectious Diseases: A Case Study of an Influenza Pandemic. PLOS ONE, 4(8), e6852. doi: 10.1371/journal.pone.0006852

Rosen, W. (2010). Justinian's flea: plague, empire and the birth of Europe: Random House.

Velavan, T. P., \& Meyer, C. G. (2020). The Covid-19 epidemic. Tropical medicine \& international health: $T M \& I H$.

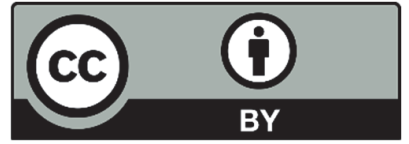

(C) 2020 by the authors; licensee Growing Science, Canada. This is an open access article distributed under the terms and conditions of the Creative Commons Attribution (CC-BY) license (http://creativecommons.org/licenses/by/4.0/). 